\title{
Dynamic testing and long term monitoring of a twelve span viaduct
}

\section{Xinghua Chen $^{1 \mathrm{a}}$, Piotr Omenzetter ${ }^{2 \mathrm{~b}}$ and Sherif Beskhyroun ${ }^{1 \mathrm{c}}$}

${ }^{1}$ Department of Civil and Environmental Engineering, The University of Auckland, New Zealand

${ }^{2}$ The LRF Centre for Safety and Reliability Engineering, University of Aberdeen, UK

\author{
axche210@aucklanduni.ac.nz \\ b piotr.omenzetter@abdn.ac.uk \\ cs.beskhyroun@auckland.ac.nz
}

Keywords: bridge; dynamic monitoring; ambient vibration testing; system identification

\begin{abstract}
Because of the critical importance of bridges in land transport networks and broader economy, an increasing interest in permanent observation of their dynamic behavior under traffic, seismic and other live loads can be observed during the past decade. In addition, recent technological advances have made the installation and operation of permanent dynamic monitoring systems much more practical and economical. A multi-channel dynamic monitoring system is being installed in the 12 span pre-cast, post-tensioned Newmarket Viaduct, recently built using the balanced cantilever method and situated in Auckland, New Zealand. This paper first reports on the preliminary experimental studies including extensive one-off ambient vibration tests using wireless sensors conducted shortly after construction of the bridge. Then the permanent monitoring system is described and proposed future research that will be undertaken using the monitoring data is outlined.
\end{abstract}

\section{Introduction}

During the past several decades, due to ageing of a large number of structures and the increasing complexity of new bridges, considerable research efforts have been devoted to the observation of the dynamic behavior of bridges. Experimental measurement tests can used to determine the structural properties at the time of opening and during the life time of the bridge under dynamic loads, such as wind, earthquake or traffic. Such tests allow comparing the dynamic characteristics assumed in the design with those of the completed structure. Also, any change in the structural performance and anomalous behavior can be determined [1].

In earlier studies, the experimental identification of relevant dynamic properties of bridges was carried out on the basis of conventional modal testing procedures previously developed and applied in the fields of mechanical, aeronautical and aerospace engineering. Such forced vibration tests involved the estimation of a set of frequency response functions (FRFs) relating the applied force and corresponding response at several pairs of points on the structure with enough high spatial and frequency resolution and required the use of equipment for structural excitation, data acquisition and signal processing [2, 3].

Although forced vibration tests may lead to very accurate modal estimates, they present a great practical challenge when dealing with large structures, as they require very heavy equipment and involve significant resources to provide controlled excitation at sufficiently high levels. This method is, therefore, usually confined to small or medium-span bridges. On the contrary, ambient vibration tests make use of environmental effects and loads, such as wind, traffic and other factors, as excitation forces and no equipment is needed to excite the bridge. For testing of large-scale bridges, ambient vibration tests are a simpler, faster and cheaper and often the only practical method for the determination of dynamic characteristics without interruption of normal traffic [4].

Despite relatively small amplitudes of response, ambient vibration tests usually provide reliable and accurate estimates of natural frequencies and mode shapes of large bridges at different stages of their life time, normally construction, commissioning or rehabilitation [5]. The estimated dynamic parameters are used for establishing correlations with numerical predictions or, in some cases, 
developing and updating of finite element models [6-9]. Such tests could also characterize the baseline structural condition, allowing subsequent detection of structural changes and damage.

However, recent technological advances have made the installation and operation of permanent dynamic monitoring systems more practical and economical and permitted an almost immediate analysis of bridge condition [10,11]. System remote control and real-time data retrieving through the Internet links are nowadays easily allowed by standard technology. These systems can presently play a very important role in the quick understanding of the structural behavior during bridge construction and service life on a day-by-day basis.

In order to profit from the latest technological developments and to have a system that is really useful for evaluation of the structure's condition, a continuous online processing of the collected data is advisable. The outputs produced can then be used as indicators of the structure's health. It is, however, often required that subsequent to the analysis of monitoring data, numerical structural models are used in order to extract the effect of environmental variables (e.g. air temperature and humidity) and, if significant, the effect of the extra mass associated with the traffic over the bridge. After elimination of the influence of these factors, changes in the dynamic characteristics can be considered to be only due to stiffness reductions associated with structural change [12].

For the design of bridges, the dynamic and vibrational load effects are especially important factors which must be carefully considered in the design. The ability to accurately predict the dynamic response of the structure to various critical transient load effects, such as wind, earthquake and traffic, is essential for a safe and high performance design. The recent construction of the Newmarket Viaduct, a major 12-span, 690m long, post-tensioned highway bridge, created an excellent opportunity to evaluate in-situ performance of such structures, and for a practical application of advanced, commercially available dynamic monitoring hardware combined with processing routines based on the latest theoretical developments.

A multi-channel dynamic monitoring system is being installed in Newmarket Viaduct to continuously evaluate the variation of its dynamic responses and properties. The final goal of the application is to show the feasibility of condition monitoring based on dynamic parameter shifts. As part of a comprehensive monitoring and research project on the behavior and performance of the Newmarket Viaduct, this paper describes experimental studies conducted before permanent monitoring system installation, characterizes the monitoring system and outlines research to be undertaken using the monitoring data.

The preliminary studies included extensive one-off ambient vibration tests using wireless sensors that provided important information for the construction of a numerical model of the bridge that will later be "tuned" to fit the bridge dynamic properties identified from the ambient vibration tests. This numerical approach is essential to improve the understanding of the structure's dynamic behavior and to create a baseline model for future condition assessment studies.

The outline of this paper is as follows. Firstly, Newmarket Viaduct and the ambient vibration tests conducted on it are described. The results of the dynamic testing exercises are reviewed. Next, the monitoring system designed for the bridge and comprising sensors to measure the dynamic responses produced by traffic is discussed. Finally, concluding remarks and future research directions are presented.

\section{Description of the bridge}

Newmarket Viaduct, recently constructed in Auckland, New Zealand, is one of the major and most important bridges within the New Zealand road network. In 2009, the average daily traffic was approximately 160,000 vehicles [13]. The total length of the bridge is $690 \mathrm{~m}$, with twelve different spans ranging in length from $38.67 \mathrm{~m}$ to $62.65 \mathrm{~m}$ and average length of approximately $60 \mathrm{~m}$. It is a horizontally and vertically curved, post-tensioned concrete bridge, comprising two parallel, twin bridges. The Northbound and Southbound Bridges are supported on independent pylons and joined together via a cast in-situ concrete 'stitch'. Now, both bridges are opened to traffic. Several views of Newmarket Viaduct appear in Figure 1. 

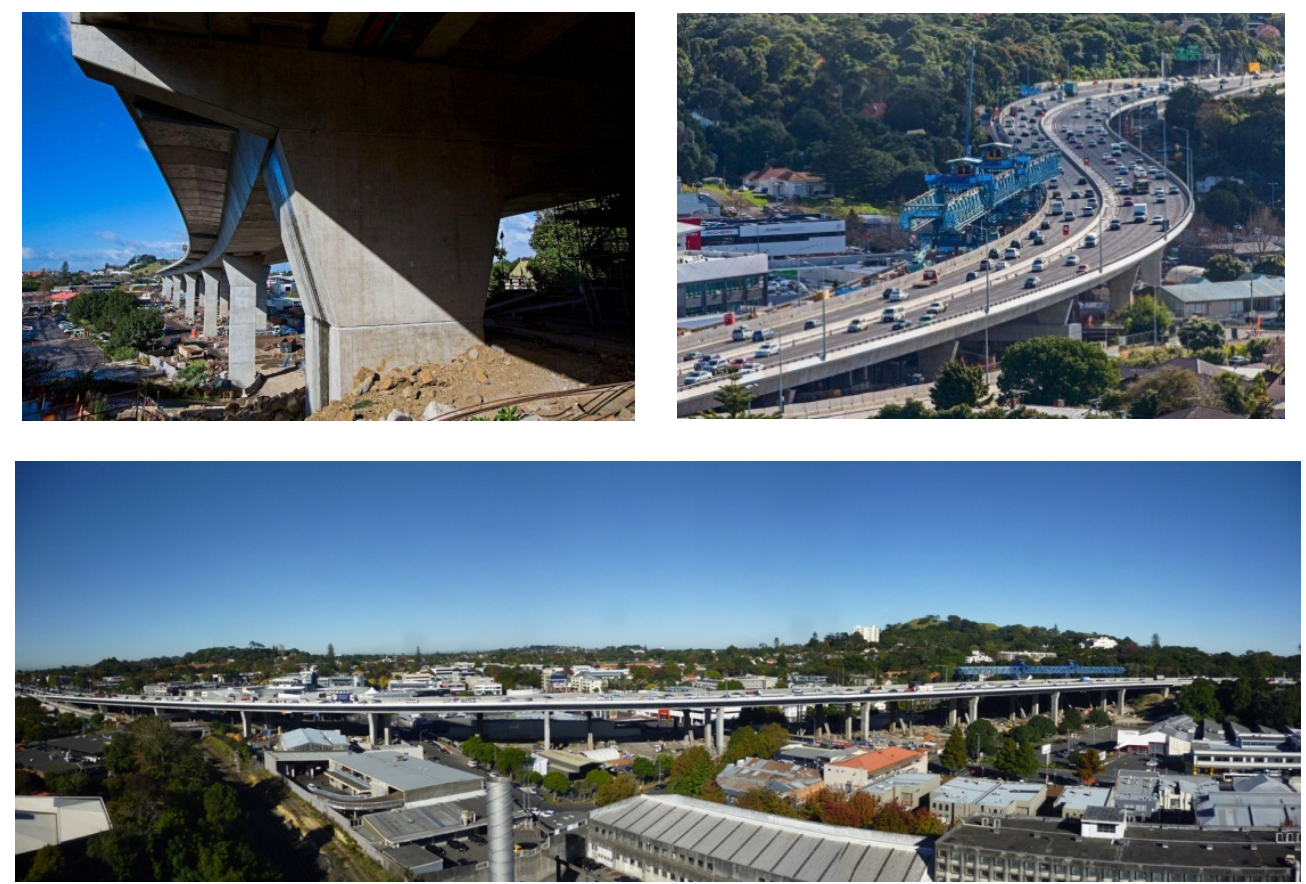

Figure 1. Views of Newmarket Viaduct [13].

\section{Ambient vibration tests}

\section{Ambient vibration test procedure}

Bridge analyses can greatly benefit from the knowledge of the structure's natural frequencies and mode shapes as well as expected levels of response due to operational conditions. The most convenient way to estimate modal parameters experimentally for a structure like Newmarket Viaduct is via an ambient vibration test. Furthermore, the data collected during these tests is of the same type as will be recorded by the continuous dynamic monitoring system, therefore similar identification algorithms can be used.

The field dynamic testing was conducted on November 29-30, 2012 under operational conditions and did not interfere with the normal flow of traffic over the bridge. It was used to determine the actual dynamic characteristics of the final constructed bridge. A total of 288 measurements points (24 for each span) on both sides inside the box girders were chosen for placing accelerometers in order to map accurately mode shapes. The accelerometers were 'lightly' glued to the internal surface of the bridge deck using silicone adhesives (Figure 2). The accelerometers used were wireless accelerometers developed by the Gulf Coast Design Concepts (http://www.gcdataconcepts.com/products.html). These accelerometers have internal storage capability but do not transmit data wirelessly; data needs to be downloaded to a computer after test completion. A maximum of 56 accelerometers for each test setup could be used simultaneously. Among these accelerometers, eight accelerometers were used as references and their locations (in span 6 and span 7 of both bridges) were not changed throughout the tests. The other 48 accelerometers were used as roving accelerometers and were moved to cover all desired locations. Six test setups were used to cover the planned testing locations of both bridges. The sampling frequency was $160 \mathrm{~Hz}$ and corresponding recording times were all approximately 1 hour for each setup. 


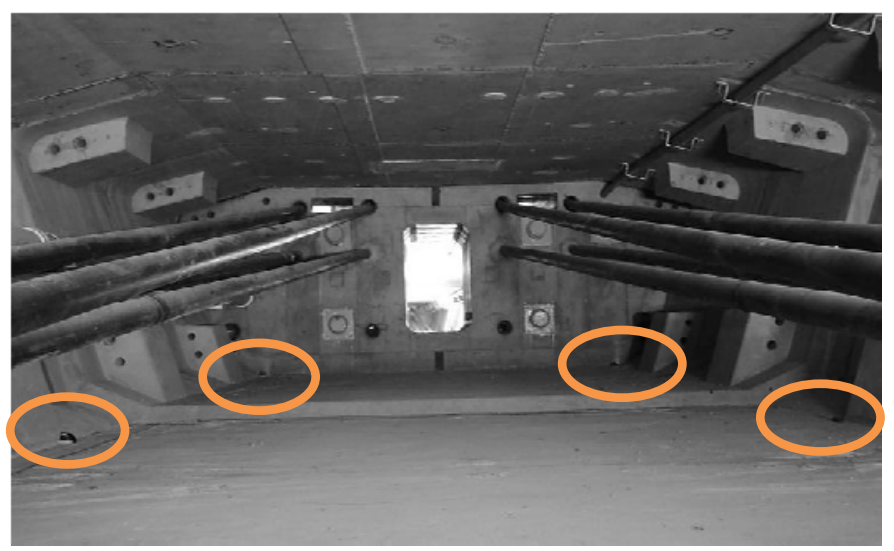

Figure 2. Location of accelerometers inside bridge girder.

\section{Identification of modal parameters}

Before applying an output-only modal identification method, the acceleration records were preprocessed with the following operations: 1) Mean removal and detrending; 2) Filtering: High pass filtering at $1 \mathrm{~Hz}$ to remove low-frequency noise and low pass filtering at $20 \mathrm{~Hz}$ with a 5 pole Butterworth filter to keep only modes of interest; and 3) Decimation from the frequency used in the tests to $50 \mathrm{~Hz}$.

Identification of modal parameters from data collected during the ambient vibration test was achieved with four separate output-only identification methods with different theoretical bases: the peak-picking and enhanced frequency domain decomposition (EFDD) in the frequency domain, and the eigenrealization algorithm combined with the natural excitation technique and stochastic subspace identification method in the time domain. A detailed description of the results provided by the four methods is presented in [14], where it is also shown that estimates of modal properties provided by the four approaches are consistent. In this paper, only the results of the EFDD method are presented, as this method is planned to be used in processing of data collected by the monitoring system.

The EFDD method procedures were applied to the peaks identified in the singular value spectra, in order to evaluate the frequencies, damping ratios and shapes of the natural modes of vibration of the viaduct $[15,16]$. The frequencies and the types of the identified modes of vibration are presented in Table 1. Figures 3 and 4 show some of the identified mode shapes.

\section{The monitoring system}

The dynamic monitoring system for Newmarket Viaduct comprises 6 variable capacitance accelerometers distributed in span 9 of the Southbound Bridge, one real-time controller with 256MB DRAM and 2GB storage and an internet modem, which will be installed inside the deck box girder as shown in Figure 5.

Table 1. Modal frequencies identified from test data

\begin{tabular}{|c|c|c|c|c|c|c|c|c|c|c|c|}
\hline Mode type & Mode number & 1 & 2 & 3 & 4 & 5 & 6 & 7 & 8 & 9 & 10 \\
\hline Vertical & Frequency (Hz) & 2.03 & 2.34 & 2.54 & 2.81 & 3.12 & 3.32 & 3.67 & 3.83 & 4.30 & 7.46 \\
\hline Transverse & Frequency (Hz) & 2.14 & 3.44 & - & - & - & - & - & - & - & - \\
\hline
\end{tabular}



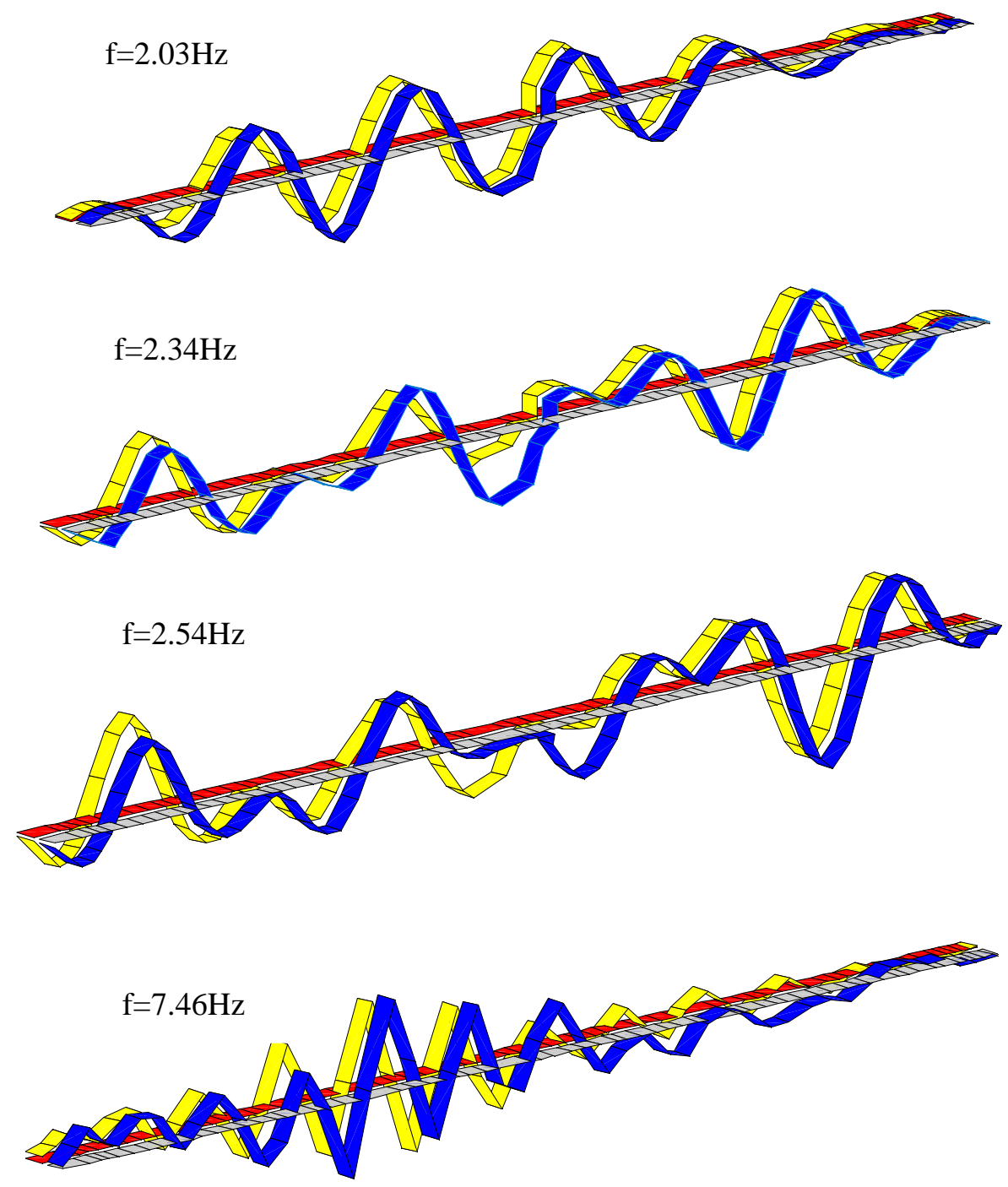

Figure 3. Views of the $1^{\text {st }}, 2^{\text {nd }}, 3^{\text {rd }}$ and $10^{\text {th }}$ vertical bending modes.

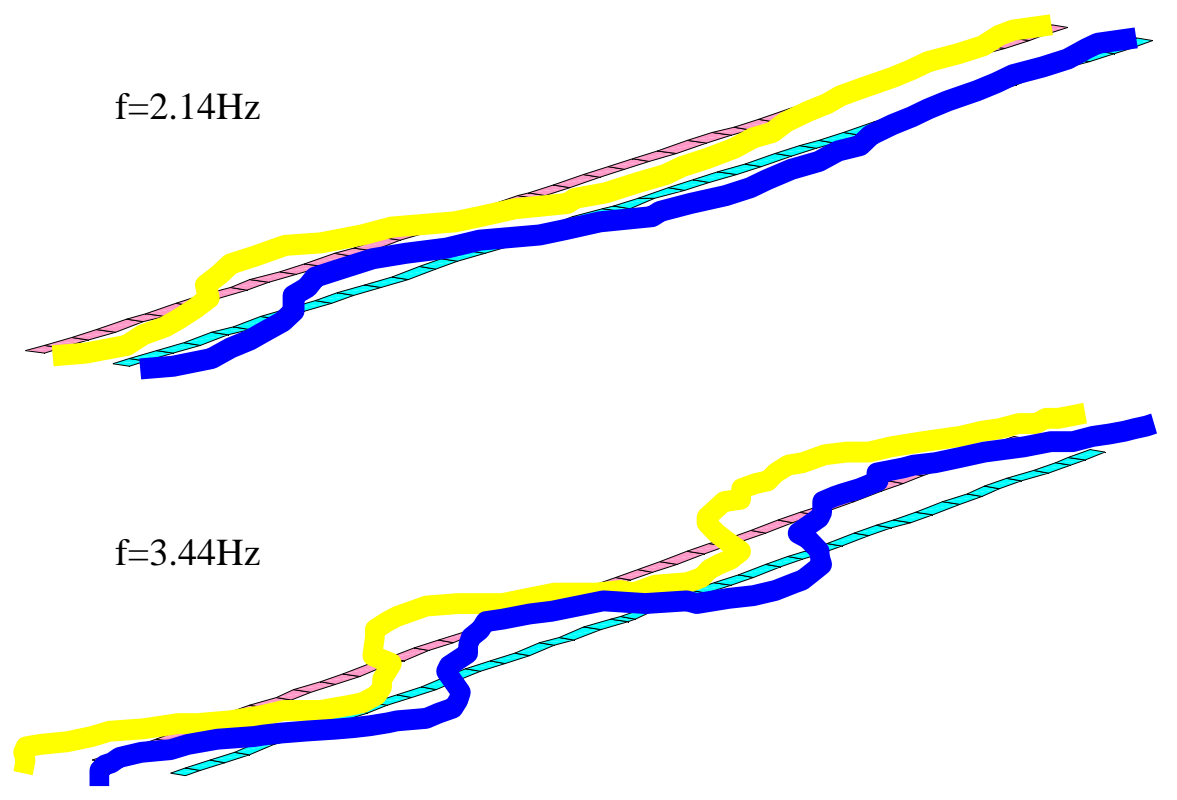

Figure 4. Views of the $1^{\text {st }}$ and 2 nd transverse bending modes. 


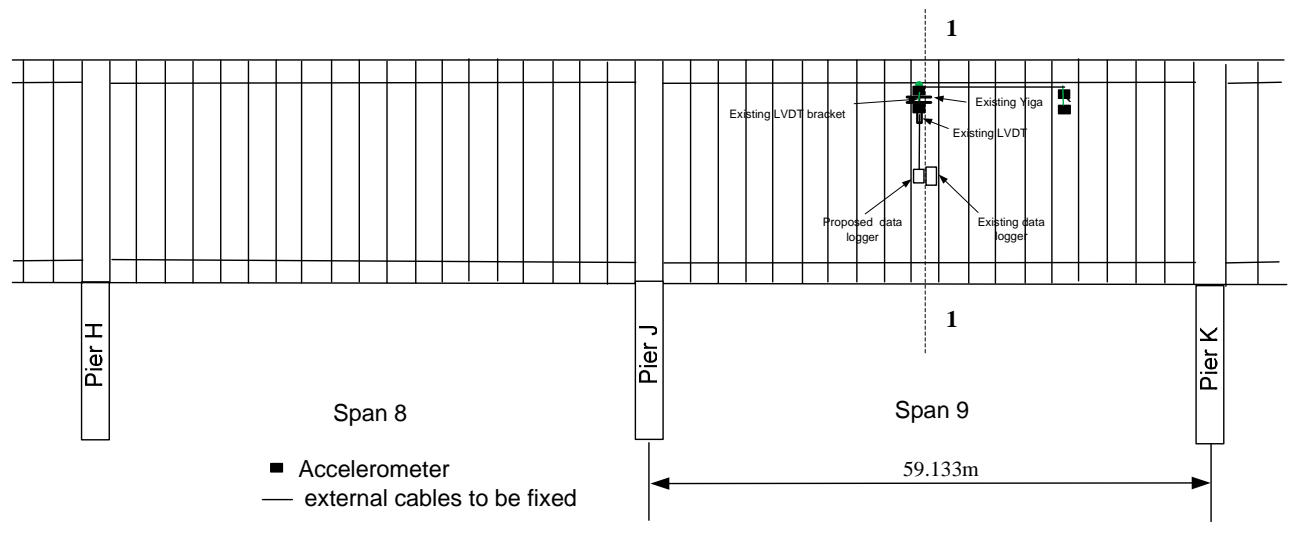

(a) Longitudinal elevation

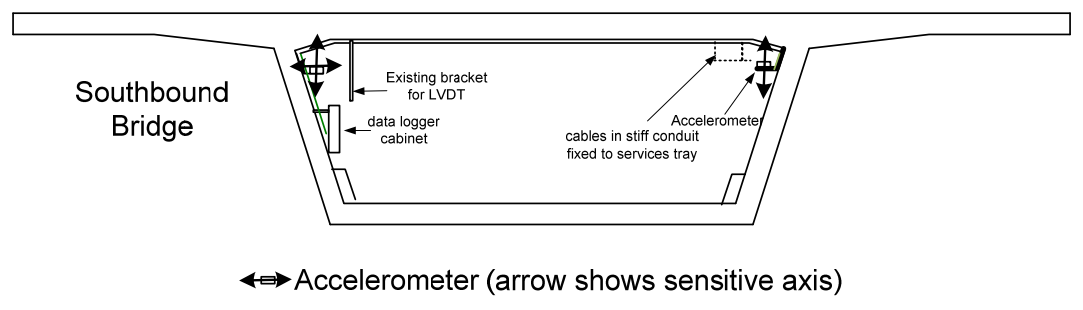

(b) Cross-section 1-1

Figure 5. Location of dynamic monitoring system components in bridge: (a) longitudinal elevation, and (b) cross section 1-1.

Since the two bridges are almost symmetric and because of budgetary constraints, we could only choose one span of the bridge for monitoring to track the first 12 natural frequencies. The reason for choosing span 9 was that it was a span with relatively large modal responses expected based on numerical bridge modeling. The six available accelerometers were distributed along two sections in the Southbound Bridge. Three sensors each are located at each section: one to measure the lateral acceleration and two for the vertical accelerations enabling determination of torsion.

The accelerometers used (Kistler K-Beam 8312B2, http://www.kistler.com/) are sensitive in the frequency range from DC to $250 \mathrm{~Hz}$ and their usable range is up to $2 \mathrm{~g}$. In the present application a measuring range between -0.25 and $+0.25 \mathrm{~g}$ was fixed, in order to optimize the sensitivity of the sensors, while staying in a conservatively estimated acceleration range (the maximum acceleration observed in the ambient test was lower than 10mg).

The real-time controller from National Instruments (http://sine.ni.com) allows the connection of six dynamic channels and is equipped with a 24-bit analog-to-digital converter, which permits simultaneous telemetry of the acquired data to a central site, and a link to a local recording unit. The recording unit guarantees that there are no data losses in case of failure of power supply or the Internet connection.

The data acquired by the real-time controller will be received at the University of Auckland, where data integration software will generate ASCII files with as many columns as the number of sensors, corresponding to the acceleration time series sampled with a predefined rate and length. For monitoring the bridge, a sampling frequency of $50 \mathrm{~Hz}$ and a length of 30min starting each day at the same time were selected. Consequently, each half an hour a new ASCII file with 12 columns and $30 \times 60 \times 50=90,000$ lines will be created at a PC located at the University of Auckland.

Finally, it is important to note that the configuration of the system (e.g. sampling frequency and length of the time segments) can be performed remotely. Data collection from the system is expected to start in May 2013 and it is planned to be continued for a foreseeable future for further research.

This dynamic monitoring system is complemented by an independent static monitoring system (performing six acquisitions per hour) that was installed in the bridge in 2010 during construction 
[17] to capture data including strains and displacements of the box girder and internal temperatures in the girder webs and flanges as well as external temperature. Four strain gauges are embedded in concrete in each of the following five cross-sections where sagging or hogging moments have the largest values: in the middle of span 8 and 9, close to their common pier and at both ends of the two spans. In Span 8 and 9 spans, baseline systems for measuring mid-span deflections are also installed. Measurements of the temperature sensors embedded in the concrete are essential for the development of numerical models that extract the effect of temperature from identified natural frequencies. Furthermore, the measurements of environmental conditions (temperature and humidity) inside and outside the box girder can also be used to investigate the effects of these variables on the identified modal parameters.

\section{Concluding remarks and future research}

This paper presents the preliminary experimental work conducted before setting up a continuous dynamic monitoring system in a 12-span concrete bridge, and characterizes the designed monitoring system. One-off ambient vibration tests were conducted to capture bridge modal properties. Later the ambient vibration test results will also be used for calibration of a numerical model of the bridge. The model, alongside dynamic monitoring data, will form the basis for assessing the structural condition by observing changes in modal parameters and interpreting them using the numerical bridge model. Time histories of strains and deflections due to creep and shrinkage, and strains and deflections due to temperature changes, all collected by the SHM system, will also be used to calibrate, or update, the numerical model of the structure. The refined model will then be used to evaluate the load rating of the current condition of Newmarket Viaduct according to proposed design loads. In the context of a monitoring program, it is very important to have good tools for continuous processing of data, in order to quickly extract parameters of interest that can then be used to evaluate the structure's health. The next step, therefore, is to develop routines for the automatic identification of modal parameters based on the monitoring data. Analysis of modal parameter changes taking into account the environmental conditions (e.g. temperature and humidity) will also be conducted.

\section{Acknowledgements}

The authors would like to express their gratitude to their supporters. Research work at the University of Auckland was partially supported by the Earthquake Commission Research Foundation grant UNI/578. Piotr Omenzetter's work within The LRF Centre for Safety and Reliability Engineering at the University of Aberdeen is supported by The Lloyd's Register Foundation (LRF). The LRF supports the advancement of engineering-related education, and funds research and development that enhances safety of life at sea, on land and in the air. NGA Newmarket facilitated the field testing and New Zealand Transport Agency allowed the use of Newmarket Viaduct for research. Gewei Chen, Shahab Ramhormozian and Peifen Chua, research students at the University of Auckland, assisted with the ambient vibration tests.

\section{References}

[1] Clemente, P., Marulo, F., Lecce, L., \& Bifulco, A. Experimental modal analysis of the Garigliano cable-stayed bridge. Soil Dynamics and Earthquake Engineering. 1998. 17(7-8), 485493.

[2] Pietrzko, S., Cantieni, R., \& Deger, Y. Modal testing of a steel/concrete composite bridge with a servo-hydraulic shaker. In Proc. $14^{\text {th }}$ International Modal Analysis Conference. 1996. Dearbon, Michigan, 91-98.

[3] Cantieni, R., \& Pietrzko, S. Modal testing of a wooden footbridge using random excitation. In Proc. of the $11^{\text {th }}$ International Modal Analysis Conference. 1991. Kissimmee, USA, 1230-1237. 
[4] Farrar, C., Duffey, T., Cornwell P., \& Doebling, S. Excitation methods for bridge structures. In Proc. of the 17th International Modal Analysis Conference. 1999. Kissimmee, Florida, 1063-1068.

[5] Cunha, A., Caetano, E., \& Magalhães, F. Output-only dynamic testing of bridges and special structures. Structural Concrete. 2007. 8(2), 67-85.

[6] Gentile, C. Modal and structural identification of a RC arch bridge, Structural Engineering and Mechanics. 2006. 22(1), 53-70.

[7] Altunisik, A., Bayraktar, A., \& Sevim, B. Output-only system identification of post tensioned segmental concrete highway bridge. Journal of Bridge Engineering. 2011. 16(2), 259-266.

[8] Liu, T., Chiang, W., Chen, C., Hsu, W., Lu, L., \& Chu, T. Identification and monitoring of bridge health from ambient vibration data. Journal of Vibration and Control. 2011. 17(4), 589-603.

[9] Magalhães, F., Caetano, E., Cunha, A., Flamand, O., \& Grillaud, G. Ambient and free vibration tests of the Millau Viaduct: Evaluation of alternative processing strategies. Engineering Structures. 2012. 45, 372-384.

[10] Wong K. Y. Instrumentation and health monitoring of cable-supported bridges. Structural Control and Health Monitoring. 2004. 11, 91-124.

[11] Ko, J. M., \& Ni, Y. Q. Technology development in structural health monitoring of large scale bridges. Engineering Structures. 2005. 27, 1715-1725.

[12] Magalhães, F., Cunha, A., \& Caetano, E. Dynamic monitoring of a long span arch bridge. Engineering Structures. 2008. 30(11), 3034-3044.

[13] Auckland Motorways. Newmarket Viaduct replacement. http://www.aucklandmotorways. co.nz/ southern/newmarketviaduct.php, accessed 20/01/2013.

[14] Chen, X., Omenzetter, P., \& Beskhyroun, S. Comparison of output-only methods for modal identification of a twelve-span viaduct. In Proc. 5th International Operational Modal Analysis Conference. 2013. Guimarães, Portugal. (in press).

[15] Bendat, J., \& Piersol, A. Random data: Analysis and measurement procedures. USA: John Wiley and Sons. 2004.

[16] Jacobsen, N., Andersen, P., \& Brincker, R. Using EFDD as a robust technique to deterministic excitation in operational modal analysis. In Proc. of the 2nd International Operational Modal Analysis Conference (IOMAC). 2007. Copenhagen, Denmark, 193-200.

[17] Chen, X., \& Omenzetter, P. A framework for reliability assessment of an in-service bridge using structural health monitoring data. Key Engineering Materials. 2013. 558, 39-51 